
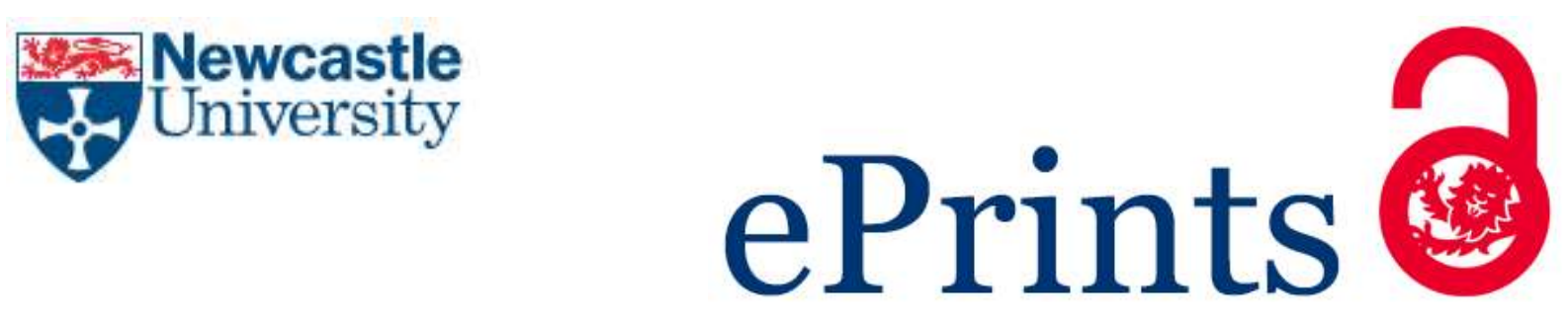

Robinson LM, Waran NK, Leach MC, Morton FB, Paukner A, Lonsdorf E, Handel I, Wilson VAD, Brosnan SF, Weiss A. Happiness is positive welfare in brown capuchins (Sapajus apella). Applied Animal Behaviour Science 2016

DOI: http://dx.doi.org/10.1016/j.applanim.2016.05.029

\title{
Copyright:
}

(C) 2016. This manuscript version is made available under the CC-BY-NC-ND 4.0 license

Date deposited:

$07 / 06 / 2016$

Embargo release date:

04 June 2017

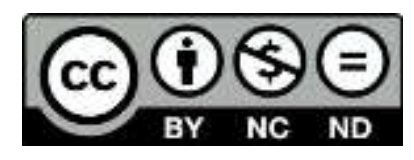

This work is licensed under a

Creative Commons Attribution-NonCommercial-NoDerivatives 4.0 International licence 
Happiness is positive welfare

\section{Happiness is positive welfare in brown capuchins (Sapajus apella)}

\section{Running title: Happiness is positive welfare}

Lauren M Robinson ${ }^{1,2,3 *}$, Natalie K Waran ${ }^{2}$, Matthew C Leach ${ }^{4}$, F Blake Morton ${ }^{3,5}$, Annika

Paukner $^{6}$, Elizabeth Lonsdorf ${ }^{5}$, Ian Handel ${ }^{7}$, Vanessa AD Wilson ${ }^{1,3}$, Sarah F Brosnan ${ }^{8}$, and

Alexander Weiss ${ }^{1,3}$

\section{$\underline{\text { Affiliations }}$}

${ }^{1}$ Department of Psychology, School of Philosophy, Psychology, and Language Sciences,

University of Edinburgh, 7 George Square, Psychology department, Edinburgh, UK, EH8 9JZ

${ }^{2}$ Jeanne Marchig International Centre for Animal Welfare Education, Royal (Dick) School of Veterinary Studies, The University of Edinburgh, Easter Bush Veterinary Centre, Roslin, UK,

\section{EH25 9RG}

${ }^{3}$ Scottish Primate Research Group, Scotland, United Kingdom

${ }^{4}$ School of Agriculture, Food \& Rural Development, Agriculture Building, Newcastle

University, Newcastle upon Tyne, UK, NE1 7RU

${ }^{5}$ Department of Psychology, Franklin \& Marshall College, Lancaster PA 17603

${ }^{6}$ Laboratory of Comparative Ethology, Eunice Kennedy Shriver National Institute of Child

Health and Human Development, Dickerson, MD 20842

${ }^{7}$ The Roslin Institute and The Royal (Dick) School of Veterinary Studies, University of Edinburgh, Roslin, UK, EH25 9RG

${ }^{8}$ Department of Psychology, Georgia State University, Atlanta, GA 30303 
Happiness is positive welfare

\section{Abstract}

Welfare questionnaires, which allow people who are familiar with individual animals to rate the welfare of the animals, are an underutilised tool. We designed a 12-item welfare questionnaire and tested its reliability and associations with subjective well-being (SWB), locomotor stereotypy, and personality traits. The welfare questionnaire included questions relating to physical health, stress and coping, satisfaction with social relationships, psychological stimulation, and the display of positive and negative welfare indicators. We collected ratings of 66 brown capuchins (Sapajus apella) living in three facilities. Each capuchin was rated on the welfare questionnaire by an average of 2.8 raters. The interrater reliability of the welfare questionnaire items ranged from $\operatorname{ICC}(3, k) 0.51$ to 0.86 . A principal components analysis indicated that the 12 welfare items loaded onto one component. We repeated this process with the welfare and subjective well-being items and found all the items were defined by a single component (welfareSWB). We then conducted three sets of analyses, one predicting the welfare component, one predicting the SWB component, and predicting the welfareSWB component. The independent variables were frequency of locomotor stereotypy, personality, age, and sex; facility was included as a random effect. In models including stereotypy, age, and sex we found frequency of stereotypy to be significantly associated with all three predicted components ( $\mathrm{p}<0.01)$. After controlling for stereotypy $(b=-0.25, \mathrm{p}=0.17)$,

44 age $(b=-0.54, \mathrm{p}=0.01)$, and $\operatorname{sex}(b=-0.32, \mathrm{p}=0.07)$, the personality traits of Sociability $(b=1.02$, $\mathrm{p}<0.001)$, Assertiveness, $(b=0.63, \mathrm{p}<0.001)$, and Attentiveness $(b=0.54, \mathrm{p}=0.01)$ were associated with higher scores on the joint welfareSWB component; Neuroticism was negatively associated $(b=-0.60, \mathrm{p}=0.01)$. Our results suggest that welfare questionnaires may

48 be a useful, reliable, and valid tool for primate welfare assessment.

49 Keywords: Brown capuchin, personality, stereotypy, subjective well-being, welfare 50 
Happiness is positive welfare

\section{Happiness is positive welfare in brown capuchins (Sapajus apella)}

People working within animal facilities are an often underutilised source of knowledge for improving animal welfare. These people use their experience to collect and interpret new information and, when shared, their observations can be used to track animal welfare. However, in spite of these capabilities there are few studies using questionnaires to assess animal welfare.

The goal of our study was to test the utility of questionnaires as a tool for assessing nonhuman primate welfare. This is an increasingly important area of research given the growing interest in assuring the welfare of animals kept in research facilities. This is also important because in order to improve animal welfare we need to be able to accurately assess it. We chose to study brown capuchin monkeys (Sapajus apella) due to the large numbers in captivity (IUCN, 2014) and the fact that there has been extensive research on their behaviour and cognition (Fragaszy et al., 2004). In particular, the personality structure of brown capuchins has been studied (Morton et al., 2013), which presented the opportunity to study the association between ratings of welfare, subjective well-being, and personality.

Animal welfare is often assessed using physiological responses and behavioural observations (Broom and Johnson, 1993; Broom, 1988). These methods have drawbacks (Rushen, 1991). For example, blood draws may be stressful, which makes measures of glucocorticoids difficult to interpret (Laule et al., 2003). Behavioural observations, although they do not disrupt the animal, are time-consuming and need to be conducted multiple times to gain an accurate assessment of an individual's welfare state (Vazire et al., 2007).

Alternatively, staff can fill out questionnaires, based on their daily observations of animals' behaviours and environmental responses, for a large number of animals in a time-efficient manner. As with other methods of welfare assessment, ratings are not perfect as raters may have individual biases. However, concerns about questionnaire reliability and validity can be assessed by testing the agreement between raters and whether responses are related to observed welfare states. If we can devise reliable and valid questionnaires for rating primate 
Happiness is positive welfare

welfare, then facilities housing primates would have one more tool for monitoring and improving welfare.

One benefit of questionnaires is that they can cover several indicators and welfare states in a relatively short period of time. In order to more effectively assess welfare it is crucial to assess multiple indices. For example, chronic stress is associated with reduced immune response (Broom, 2006; Cohen et al., 1992) and increased incidence of self-injury (Davenport et al., 2008; Lutz et al., 2003). There is also increased focus on accounting for the experience of positive emotions (or happiness) in welfare assessment (Boissy et al., 2007). A primate welfare questionnaire that covers a diverse set of welfare indicators, including those relating to both positive and negative welfare, could be used to further investigate how different aspects of welfare are interconnected.

One questionnaire designed to assess happiness in nonhuman primates is King and Landau's subjective well-being questionnnaire (SWB) (2003), which was based on studies of human happiness (Sandvik et al., 1993). This questionnaire was initially used to assess chimpanzees (King and Landau, 2003) and has since been used with other nonhuman species such as felids (Gartner and Weiss, 2013) and other nonhuman primates (Weiss et al., 2011a, 2011b, 2006). These studies have shown that the interrater and retest reliabilities of animal SWB are similar to those of humans (Diener, 2009). Also, as in humans (Diener and Chan, 2011; Diener et al., 2003), happier animals (those with higher SWB) tend to live longer (Weiss et al. 2011) and share certain personality traits, such as higher Extraversion (King and Landau, 2003; Weiss et al., 2009, 2006). In humans happiness and welfare are directly associated with one another (Diener, 2009) suggesting that they are measuring similar constructs. Both animal welfare and SWB involve the animal's ability to cope with their environment and the balance of positive and negative experiences (Broom, 2007; King and Landau, 2003). Does this mean SWB is equivalent to animal welfare? By assessing welfare and SWB in brown capuchins, we can determine the degree to which these constructs are related in this species. 
Happiness is positive welfare

Accounting for variation in personality has been suggested as another way of understanding and improving captive animal welfare (Tetley and O'Hara, 2012). Studying personality and welfare together may help researchers better understand why animals in a shared environment may have vastly different welfare states. Until now the five brown capuchin personality traits (Assertiveness, Openness, Neuroticism, Sociability, and Attentiveness) have not been studied in connection with welfare and SWB. questionnaire in brown capuchins. We then examined the convergence of ratings of welfare and happiness. Finally, we tested the association of ratings of welfare and SWB with locomotor stereotypy and personality traits.

\subsection{Ethical Approval}

This project was approved by the participating facilities in July 2014. This study was non-invasive and complied with the US Animal Welfare Act (USDA, 2008).

\subsection{Subjects}

Subjects were 66 brown capuchins (31 males) housed at the National Institutes of Health, Georgia State University, and Franklin \& Marshall College. Ages ranged from 0.55 years to 45.56 years (mean $\pm \mathrm{SD}=12.47$ years \pm 9.03 years). Across the facilities all the capuchins were socially housed in groups or pairs.

\subsection{Instruments}

\subsubsection{Welfare questionnaire.}

We designed the welfare questionnaire with practicality in mind, and so it was relatively brief and applicable to multiple primate species. The questionnaire is comprised of three sections. The first section asks raters, who were caretakers or other individuals with extensive experience working with the animals that they rated, to answer questions about their experience working with animals. In addition, to prime raters for the welfare questions, this section of the questionnaire asks which physical and behavioural indicators raters use to 
Happiness is positive welfare

determine whether an animal has positive or negative welfare. The second section consisted of 12 questions based on the five major contributors to animal quality of life proposed by McMillan (2005), including social relationships, mental stimulation, health, stress, and control of the social and physical environment. Some of the definitions and wording were influenced by work by Broom (2007, 1991), Broom and Johnson (1993), and by Green and Mellor (2011). Each of the items could be rated on a five point Likert scale ranging from very bad to very good, altered to fit the question wording and to capture negative and positive welfare states (Boissy et al., 2007; Yeates and Main, 2008). Each question also included a section for comments. The welfare questionnaire is available in Appendix 1. 2.3.2 Subjective well-being ratings.

We collected subjective well-being ratings for the capuchins using a four-item questionnaire based on King and Landau's questionnaire ${ }^{1}$ (2003). This questionnaire asks raters to estimate how often each animal is happy, how satisfying each animal finds their social experiences, how successful the animal is at achieving its goals, and to imagine how happy they would be if they were that animal for a week. Raters used a seven point Likert scale to rate how well each adjective describes the individual animals from "Displays either total absence or negligible amounts of the trait or state" to "Displays extremely large amounts of the trait".

\subsubsection{Personality ratings.}

We collected personality ratings using the Hominoid Personality Questionnaire ${ }^{2}$, a 54-item questionnaire where each item consists of an adjective and one to three descriptive sentences (Weiss et al., 2011b). For example, the item 'fearful' is "FEARFUL: Subject reacts excessively to real or imagined threats by displaying behaviours such as screaming, grimacing, running away, or other signs of anxiety or distress.” The HPQ uses a seven point

\footnotetext{
${ }^{1}$ The SWB questionnaire can be found at http://extras.springer.com/2011/978-1-4614-01759/weiss_monkey_wellbeing.pdf

2 The HPQ can be found at http://extras.springer.com/2011/978-1-4614-0175-

9/weiss_monkey_personality.pdf
} 
Happiness is positive welfare

Likert scale from "Displays either total absence or negligible amounts of the trait" to

"Displays extremely large amounts of the trait".

2.3.4 Stereotypic behaviour.

We collected data on the frequency of locomotor stereotypy to test the welfare and

SWB questionnaires' relation to an observable welfare state. We asked staff to "Rate how often each animal performs any of the following behaviours by placing an $\mathrm{X}$ in the appropriate column". This was followed by operational definitions taken from Vandeleest et al. (2011) for the following stereotypies: pace, flip, twirl, swing, bounce, head twist, and rock. Staff then rated each capuchins' stereotypic behaviour on a five point frequency scale from "never" to "constantly".

\subsection{Data Collection}

We collected welfare questionnaires and subjective well-being ratings from 7 May 2014 to 28 August 2014. Ten raters performed 185 ratings of the 66 capuchins using the welfare questionnaire (mean=2.80 ratings per capuchin); nine raters performed 181 ratings using the SWB questionnaire (mean=2.70 ratings per capuchin). Raters knew each capuchin for an average of 3.88 years (range: 0.50 years to 16 years, $S D \pm 3.81$ years). There were 19 missing data points out of 2220 possible welfare responses and no missing data points out of 724 possible SWB responses. At the same time we collected 64 personality ratings of 18 animals. We used 140 personality ratings of 48 of these capuchins previously collected in 2010 and reported in Morton et al. (2013). Each of the 66 capuchins was rated on average 3.25 times; three animals were only rated once. Overall there were 230 missing data points out of 11016 possible personality responses. Lastly, in December, 2015 we collected 172 ratings of stereotypy frequency from seven raters (mean=2.61 raters per animal); there were no missing data points. All seven raters had contributed to the 2014 data collection. The stereotypy ratings were collected later than the other questionnaires as we decided to test the welfare and SWB questionnaires' validity by connecting it an observable welfare state, in this case stereotypy. Raters for all the questionnaires were researchers, care staff and/or students 
Happiness is positive welfare

familiar with individual animals. For all the questionnaires any item with a missing value was replaced with that items' mean score (Downey and King, 1998).

\subsection{Analysis}

Statistical analyses were performed using R, version 3.1.1 (R Development Core Team, 2014).

\subsubsection{Intraclass correlations.}

We used intraclass correlations (ICCs) to assess the interrater reliability of welfare and SWB ratings of the 48 animals that were assessed by multiple raters; the same animals were in both analyses. We also performed ICCs to assess the reliability of the personality items for the 63 capuchins that were assessed by multiple raters. $I C C(3,1)$ estimates the reliability of single ratings and $\operatorname{ICC}(3, k)$ assesses the reliability across mean ratings based on $k$ raters (Shrout and Fleiss, 1979).

\subsubsection{Principal components analyses.}

We averaged the welfare item scores across raters leaving a single score per animal and then conducted separate principal component analyses (PCA) for the welfare items and the SWB items. We determined the number of components to extract by examining the scree plot and performing a parallel analysis (Dinno and Dinno, 2010; Horn, 1965). We then computed unit-weighted component scores (Gorsuch, 1983) by assigning a weight of +1 to loadings that were greater than or equal to .4 and a weight of -1 to loadings that were less than or equal to -.4. All other loadings were assigned weights of 0 . In the event that an item had a loading greater than or equal to $|.4|$ on more than one component, we assigned the item to the component on which it had the highest loading. We then performed a joint-PCA with the 12 welfare items and the four SWB items.

To calculate personality component scores we aggregated HPQ item scores across raters and generated component scores for the personality dimensions based on the 2013 published structure (Table 6 in Morton et al. 2013). This structure includes five brown capuchin personality dimensions: Assertiveness is made up of items such as bullying, aggressive, and dominant; Openness is made up of items such as inventive, innovative, and 
Happiness is positive welfare

playful; Neuroticism is made up of items such as (not) stable, (not) predictable, and excitable;

214 Sociability which includes affectionate, friendly, and (not) solitary; Attentiveness is made up of items such as (not) disorganised, (not) unperceptive, and (not) thoughtless.

\subsubsection{Pearson correlations.}

To examine the associations between personality, welfare, and SWB we used Pearson correlations. After standardising the variables we correlated the personality dimensions and the welfare and SWB items and components. We interpreted the results adjusted for multiple tests using a Holm-Bonferroni correction.

\subsubsection{Generalizable linear models.}

We fit linear mixed-effects models using the nlme package (Pinheiro et al., 2012). In all models we included age and sex as fixed effects and facility as a random effect. Our dependent variables were the component scores based on the results of the PCAs of the welfare and SWB items Each of these models included three combinations of fixed effects: 1) locomotor stereotypy frequency; 2) the five capuchin personality dimensions; 3) the five personality dimensions and locomotor stereotypy frequency. Locomotor stereotypy frequency was included in models as the aggregation of stereotypy scores across raters. Housing was not included in our models as only three capuchins were reported to ever be pair-housed, the rest were group housed. The dependent variables were converted into z-scores (mean $\pm \mathrm{SD}=0 \pm$ 1). The continuous predictor variables (stereotypy, age, and personality dimension) were centred and divided by $2 * \mathrm{SD}$ to make the effect size more comparable with the binary variable (sex) (Gelman, 2008). We then calculated conditional $\mathrm{R}^{2}$, which gives the variation explained by the fixed and random effects in the model, using the MuMIn package (Barton,

\subsection{Items Interrater Reliabilities} the $\operatorname{ICC}(3, k)$ ranged from 0.51 to 0.86 with a mean of 0.72 (Table 1). For the SWB items the 
Happiness is positive welfare

$241 \operatorname{ICC}(3,1)$ ranged from 0.51 to 0.74 with a mean of 0.63 and the $\operatorname{ICC}(3, k)$ ranged from 0.78 to

2420.91 with a mean of 0.85 (Table 1). For the HPQ items the $\operatorname{ICC}(3,1)$ ranged from 0.12 to 0.74

243 with a mean of 0.39 and the $\operatorname{ICC}(3, k)$ ranged from 0.30 to 0.90 with a mean of 0.64 (S1). For

244 ratings of stereotypic behaviour the $\operatorname{ICC}(3,1)$ was 0.64 and $\operatorname{ICC}(3, k)$ was $0.82(k=2.61)$.

246 Table 1

247 Interrater reliability of welfare and SWB items

\begin{tabular}{lcc}
\hline Item & $I C C(3,1)$ & $I C C(3, k)$ \\
\hline Social control & 0.63 & 0.86 \\
Number of relationships & 0.63 & 0.86 \\
Physical health & 0.56 & 0.82 \\
Positive/negative experience & 0.53 & 0.80 \\
Quality of relationships & 0.49 & 0.77 \\
Positive welfare & 0.46 & 0.75 \\
Stress frequency & 0.46 & 0.75 \\
Negative welfare & 0.45 & 0.74 \\
Environmental control & 0.37 & 0.67 \\
Effect of experience & 0.31 & 0.61 \\
Psychological stimulation & 0.26 & 0.55 \\
Stress coping & 0.23 & 0.51 \\
\hline Welfare average & 0.45 & 0.72 \\
\hline & & \\
SWB Goal achievement & 0.74 & 0.91 \\
SWB Happiness as animal & 0.64 & 0.86 \\
SWB Time animal is happy & 0.63 & 0.85 \\
SWB Social satisfaction & 0.51 & 0.78 \\
\hline SWB Average & 0.63 & 0.85 \\
\hline
\end{tabular}

Note. Based on 48 brown capuchins. Welfare items $k=3.48$.

SWB items $k=3.33$.

\section{3.2 PCA of Welfare Items and SWB Items}

A parallel analysis and scree plot of the welfare items showed a single component

251 (Table 2). When we included both the welfare and SWB items in a joint-PCA we again found

252 a single component. All 16 items had salient loadings on this component (Table 3); we named

253 this component welfareSWB. 
Happiness is positive welfare

$257 \quad$ Table 2

258 PCA of brown capuchin welfare items

259

\begin{tabular}{lrl}
\hline Item & Loading & $h^{2}$ \\
\hline Positive/negative experience & 0.93 & 0.87 \\
Number of relationships & 0.93 & 0.86 \\
Stress frequency & -0.90 & 0.81 \\
Negative welfare & -0.84 & 0.71 \\
Positive welfare & 0.84 & 0.70 \\
Quality of relationships & 0.83 & 0.69 \\
Social control & 0.82 & 0.67 \\
Environmental control & 0.80 & 0.65 \\
Stress coping & 0.72 & 0.52 \\
Psychological stimulation & 0.61 & 0.38 \\
Effect of experience & 0.60 & 0.36 \\
Physical health & 0.50 & 0.25 \\
\hline
\end{tabular}

260 Note. $\mathrm{N}=66$. Proportion of variance $=62 \% \cdot h^{2}=$ commonalities

261

262 Table 3

263 PCA of brown capuchin welfare and subjective well-being items

\begin{tabular}{lrl}
\hline Item & Loading & $h^{2}$ \\
\hline SWB Happiness as animal & 0.93 & 0.87 \\
Number of relationships & 0.93 & 0.87 \\
SWB Time animal is happy & 0.92 & 0.85 \\
Positive/negative experience & 0.92 & 0.85 \\
Stress frequency & -0.90 & 0.80 \\
SWB Social satisfaction & 0.88 & 0.78 \\
SWB Goal achievement & 0.85 & 0.73 \\
Social control & 0.84 & 0.71 \\
Quality of relationships & 0.83 & 0.70 \\
Positive welfare & 0.83 & 0.69 \\
Negative welfare & -0.82 & 0.68 \\
Environmental control & 0.76 & 0.58 \\
Stress coping & 0.74 & 0.54 \\
Effect of experience & 0.59 & 0.35 \\
Psychological stimulation & 0.57 & 0.33 \\
Physical health & 0.49 & 0.24 \\
\hline Note. No66. Proportion of vaiance explaned & & $66 \%$
\end{tabular}

264 Note. $\mathrm{N}=66$. Proportion of variance explained $=66 \% \cdot h^{2}=$ commonalities 
Happiness is positive welfare

\subsection{Pearson Correlations of Welfare, SWB, and Personality}

268 The welfare component and SWB component were highly correlated ( $r=0.91$, $\mathrm{p}<0.001,95 \%$ CI 0.86 to 0.95$)$. Higher Sociability correlated with the higher welfare, higher SWB, and higher welfareSWB scores (Table 4); capuchins rated as more sociable were rated as having better welfare and higher happiness. Assertiveness correlated with the SWB component but not the welfare or welfareSWB components. The full correlation matrix including all items and components is available in Supplementary Table 2. 
Happiness is positive welfare

\section{Table 4}

276 Pearson correlation coefficients of brown capuchin personality components and welfare and SWB components

\begin{tabular}{lcccccc}
\hline Component & Welfare & $95 \%$ CI & SWB & $95 \%$ CI & WelfareSWB & $95 \%$ CI \\
\cline { 2 - 7 } Assertiveness & $\mathbf{0 . 3 7}$ & {$[0.14,0.56]$} & $\mathbf{0 . 4 9}$ & {$[0.28,0.65]$} & $\mathbf{0 . 4 1}$ & {$[0.18,0.59]$} \\
Openness & 0.25 & {$[0.01,0.46]$} & 0.27 & {$[-0.03,0.48]$} & 0.26 & {$[0.02,0.47]$} \\
Neuroticism & -0.28 & {$[-0.49,-0.05]$} & -0.24 & {$[-0.46,0.00]$} & -0.28 & {$[-0.49,-0.04]$} \\
Sociability & $\mathbf{0 . 7 2}$ & {$[0.58,0.82]$} & $\mathbf{0 . 6 9}$ & {$[0.54,0.80]$} & $\mathbf{0 . 7 2}$ & {$[0.58,0.82]$} \\
Attentiveness & -0.19 & {$[-0.41,0.05]$} & -0.22 & {$[-0.44,0.02]$} & -0.21 & {$[-0.43,0.04]$} \\
\hline
\end{tabular}

277 Note. $\mathrm{N}=66$. Boldface values were significant at $\mathrm{p}<0.01$. Adjusted for multiple tests. 
Happiness is positive welfare

\subsection{Mixed-Effects Models}

279 3.4.1 Welfare. performed locomotor stereotypies more frequently were rated as being significantly lower in welfare (see Table 5, left panel). In both the model with the five personality dimensions and in the model that included stereotypy frequency, capuchins lower in Neuroticism and higher in Sociability, Assertiveness, and Attentiveness were rated as having significantly better welfare (see Table 5, middle and right panels). 
Happiness is positive welfare

286 Table 5

287 Models of brown capuchin welfare component predicted by stereotypy and personality, controlling for age and sex with facility as a random effect

\begin{tabular}{lccccccccc}
\hline Predictor & $b$ & $\mathrm{CI}$ & $\mathrm{p}$ & $b$ & $\mathrm{CI}$ & $\mathrm{p}$ & $b$ & $\mathrm{CI}$ \\
\cline { 2 - 9 } Intercept & 0.18 & {$[-0.22,0.58]$} & 0.042 & 0.17 & {$[0.07,0.42]$} & 0.008 & 0.16 & {$[-0.06,0.39]$} & 0.003 \\
Stereotypy & -0.77 & {$[-1.21,-0.33]$} & $<\mathbf{0 . 0 0 1}$ & --- & --- & -- & -0.26 & {$[-0.63,0.10]$} & 0.16 \\
Age & -0.55 & {$[-1.00,-0.10]$} & $\mathbf{0 . 0 1 8}$ & -0.58 & {$[-1.00,-0.15]$} & $\mathbf{0 . 0 0 9}$ & -0.57 & {$[-0.99,-0.15]$} & $\mathbf{0 . 0 0 9}$ \\
Male & -0.36 & {$[-0.80,0.08]$} & 0.11 & -0.38 & {$[-0.72,-0.04]$} & $\mathbf{0 . 0 3 1}$ & -0.35 & {$[-0.69,-0.01]$} & $\mathbf{0 . 0 4 5}$ \\
Sociability & --- & --- & --- & 1.21 & {$[0.76,1.65]$} & $<\mathbf{0 . 0 0 1}$ & 1.03 & {$[0.54,1.53]$} & $<\mathbf{0 . 0 0 1}$ \\
Assertiveness & --- & --- & --- & 0.56 & {$[0.20,0.92]$} & $\mathbf{0 . 0 0 3}$ & 0.56 & {$[0.20,0.92]$} & $\mathbf{0 . 0 0 3}$ \\
Openness & --- & --- & --- & -0.28 & {$[-0.76,0.20]$} & 0.23 & -0.16 & {$[-0.67,0.35]$} & 0.53 \\
Neuroticism & --- & --- & --- & -0.55 & {$[-1.03,-0.07]$} & $\mathbf{0 . 0 2 5}$ & -0.63 & {$[-1.11,-0.14]$} & $\mathbf{0 . 0 1 2}$ \\
Attentiveness & --- & --- & --- & 0.58 & {$[0.16,1.01]$} & $\mathbf{0 . 0 0 8}$ & 0.58 & {$[0.16,1.00]$} & $\mathbf{0 . 0 0 7}$ \\
\hline
\end{tabular}

Note. $\mathrm{N}=66$. Boldface values were significant at $\mathrm{p}<0.05$. Variance explained: left panel: $R^{2}=0.31$, middle panel: $R^{2}=0.62$, right panel: $R^{2}=0.62$. 


\section{Happiness is positive welfare}

3.4.2 SWB. performed more stereotypy were rated as as having significantly lower SWB (see Table 6, left panel). In both the model with the five personality dimensions and the model including the personality dimensions and stereotypy, capuchins with higher Sociability and Assertiveness were rated as having significantly higher SWB (see Table 6, middle and right panels). None of the other personality traits were significantly associated with SWB. 
Happiness is positive welfare

296 Table 6

297 Models of brown capuchin SWB component predicted by stereotypy and personality, controlling for age and sex with facility as a random effect

\begin{tabular}{lccccccccc}
\hline Predictor & $b$ & $\mathrm{CI}$ & $\mathrm{p}$ & $b$ & $\mathrm{CI}$ & $\mathrm{p}$ & $b$ & $\mathrm{CI}$ & $\mathrm{p}$ \\
\cline { 2 - 9 } Intercept & 0.09 & {$[-0.23,0.40]$} & 0.091 & 0.10 & {$[-0.18,0.39]$} & 0.10 & 0.10 & {$[-0.17,0.36]$} & 0.099 \\
Stereotypy & -0.68 & {$[-1.14,0.21]$} & $\mathbf{0 . 0 0 5}$ & --- & --- & --- & -0.19 & {$[-0.58,0.19]$} & 0.32 \\
Age & -0.48 & {$[-0.94,-0.01]$} & $\mathbf{0 . 0 4 6}$ & -0.40 & {$[-0.85,0.05]$} & 0.079 & -0.40 & {$[-0.84,0.05]$} & 0.078 \\
Male & -0.18 & {$[-0.65,0.29]$} & 0.44 & -0.24 & {$[-0.59,0.11]$} & 0.18 & -0.22 & {$[-0.58,0.14]$} & 0.22 \\
Sociability & --- & --- & --- & 1.13 & {$[0.66,1.59]$} & $<\mathbf{0 . 0 0 1}$ & 0.99 & {$[0.47,1.51]$} & $<\mathbf{0 . 0 0 1}$ \\
Assertiveness & --- & --- & --- & 0.79 & {$[0.42,1.16]$} & $<\mathbf{0 . 0 0 1}$ & 0.79 & {$[041,1.16]$} & $<\mathbf{0 . 0 0 1}$ \\
Openness & --- & --- & -- & -0.23 & {$[-0.72,0.26]$} & 0.35 & -0.14 & {$[-0.67,0.39]$} & 0.59 \\
Neuroticism & --- & --- & --- & -0.40 & {$[-0.90,0.10]$} & 0.11 & -0.45 & {$[-0.96,0.05]$} & 0.079 \\
Attentiveness & --- & --- & --- & 0.44 & {$[-0.01,0.88]$} & 0.056 & 0.42 & {$[-0.03,0.86]$} & 0.066 \\
\hline
\end{tabular}

298 Note. $\mathrm{N}=66$. Boldface values were significant at $\mathrm{p}<0.05$. Variance explained: left panel: $R^{2}=0.19$, middle panel: $R^{2}=0.60$, right panel: $R^{2}=0.60$. 
Happiness is positive welfare

3.4.3 WelfareSWB.

In the model that included stereotypy we found that capuchins who displayed

301 stereotypic behaviour more frequently were rated as being significantly lower in welfareSWB (see Table 7, left panel). In the model that included the five personality traits we found that capuchins higher in Sociability, Assertiveness, and Attentiveness and lower in Neuroticism had significantly higher welfareSWB (see Table 7, middle panel). Finally, in the model with the five personality dimensions and stereotypy we again found higher Sociability, Assertiveness, and Attentiveness dimensions and lower Neuroticism were significantly related to higher ratings of welfare and SWB (see Table 7, right panel). 
Happiness is positive welfare

$309 \quad$ Table 7

310 Models of brown capuchin welfareSWB component predicted by stereotypy and personality, controlling for age and sex with facility as a random effect

\begin{tabular}{lccccccccc}
\hline Predictor & $b$ & $\mathrm{CI}$ & $\mathrm{p}$ & $b$ & $\mathrm{CI}$ & $\mathrm{p}$ & $b$ & $\mathrm{CI}$ \\
\cline { 2 - 8 } Intercept & 0.15 & {$[-0.22,0.53]$} & 0.047 & 0.15 & {$[-0.10,0.40]$} & 0.015 & 0.15 & {$[-0.08,0.38]$} & 0.014 \\
Stereotypy & -0.76 & {$[-1.20,-0.31]$} & $\mathbf{0 . 0 0 1}$ & --- & --- & --- & -0.25 & {$[-0.62,0.11]$} & 0.17 \\
Age & -0.54 & {$[-1.00,-0.09]$} & $\mathbf{0 . 0 2 0}$ & -0.54 & {$[-0.97,-0.12]$} & $\mathbf{0 . 0 1 3}$ & -0.54 & {$[-0.96,-0.12]$} & $\mathbf{0 . 0 1 3}$ \\
Male & -0.31 & {$[-0.76,0.14]$} & 0.17 & -0.34 & {$[-0.68,-0.00]$} & $\mathbf{0 . 0 4 8}$ & -0.32 & {$[-0.65,0.02]$} & 0.070 \\
Sociability & --- & --- & --- & 1.19 & {$[0.75,1.63]$} & $<\mathbf{0 . 0 0 1}$ & 1.02 & {$[0.53,1.51]$} & $<\mathbf{0 . 0 0 1}$ \\
Assertiveness & --- & --- & --- & 0.63 & {$[0.28,0.99]$} & $<\mathbf{0 . 0 0 1}$ & 0.63 & {$[0.28,0.98]$} & $<\mathbf{0 . 0 0 1}$ \\
Openness & --- & --- & --- & -0.24 & {$[-0.73,0.22]$} & 0.28 & -0.14 & {$[-0.64,0.36]$} & 0.57 \\
Neuroticism & --- & --- & --- & -0.53 & {$[-1.01,-0.06]$} & $\mathbf{0 . 0 2 9}$ & -0.60 & {$[-1.08,-0.13]$} & $\mathbf{0 . 0 1 4}$ \\
Attentiveness & --- & --- & --- & 0.55 & {$[0.12,0.97]$} & $\mathbf{0 . 0 1 3}$ & 0.54 & {$[0.12,0.95]$} & $\mathbf{0 . 0 1 3}$ \\
\hline
\end{tabular}

311 Note. $\mathrm{N}=66$. Boldface values were significant at $\mathrm{p}<0.05$. Variance explained: left panel: $R^{2}=0.28$, middle panel: $R^{2}=0.63$, right panel: $R^{2}=0.63$. 
Happiness is positive welfare

\subsubsection{Sensitivity test}

We conducted sensitivity tests of the models by removing the 18 capuchins that had been concurrently rated on the welfare, SWB, and HPQ questionnaires. We found some effects were no longer significant. However, the effect sizes were largely similar suggesting this was due to loss of statistical power. See Supplementary Tables 3-5 for full models.

\section{Discussion}

We found there was good evidence for staff agreement of ratings of welfare. The welfare items formed a single component. The welfare ratings were correlated with ratings of SWB and formed a single component with SWB items. These results suggest that ratings of happiness and welfare ratings are indistinguishable in brown capuchins. Welfare and SWB ratings were associated with the exhibition of stereotypic behaviour. Finally, four of the five brown capuchin personality dimensions were associated with their welfare, even after adjusting for the presence of locomotor stereotypies. In all models the effect of Sociability and Assertiveness was larger than age, sex, and stereotypy.

These findings suggest that facilities housing animals can make use of the knowledge and experience of their staff to collect additional data on animal welfare. The reliability of ratings were relatively high and on par with reliabilities with those in studies of human personality and subjective well-being (Diener, 2009; Gosling, 2001). As suggested by other authors, our results demonstrate that staff members are reliable, credible, and valuable sources of welfare data (Meagher, 2009; Whitham and Wielebnowski, 2009). Additionally, the welfare questionnaire was reported to take as little as three minutes showing the utility of questionnaires as a quick addition to traditional assessment methods. In the future we can expand on this research by examining the validity of welfare ratings in other nonhuman primate species.

The welfare items formed a single component suggesting that the aspects of welfare that our questionnaire covered (stress coping, physical health, control, etc.) are connected. Lower welfare and SWB ratings were associated with the higher frequency of stereotypic 
Happiness is positive welfare

behaviour. As stereotypy is an abnormal behaviour specific to captivity (Mason, 1991) this suggests that the SWB and welfare questionnaires are measuring an observed welfare state. An alternative explanation may be that raters are familiar with the literature surrounding stereotypy and see it as a negative welfare indicator. Raters who had noted stereotypies were presumably more likely to rate that animal lower in welfare and SWB thus biasing ratings downward. This may be problematic as the literature is mixed regarding the validity of stereotypy as a negative welfare indicator (Mason and Latham, 2004; Mason, 1991). The fact that our stereotypy results validated our welfare and SWB measures still indicates the utility of the measure, but highlights the need for additional metrics that may be less obvious to observers, such as stress hormone levels, to provide further validation. importance of primate sociality. Socially deprived primates are prone to self-injury and are at greater risk of displaying stereotypies (Gottlieb et al., 2013; Lutz et al., 2003). Conversely, primates who create high quality social relationships benefit in terms of their psychological and physical health. For example, they have lower stress levels (Shutt et al., 2007; Terry, 1970) and reduced parasite loads (Akinyi et al., 2013; Crofoot et al., 2011). between Assertiveness and welfare rating may be connected to rank, as a previous study of 38 of these subjects found that Assertiveness and alpha status were associated (Lefevre et al., 2014). Within some primate species high rank confers advantages that may lead to better welfare, including primary access to food (Boccia et al., 1988; Janson, 1985; Wittig and Boesch, 2003) and grooming (Coelho Jr et al., 1983; Leinfelder et al., 2001; Parr et al., 1997), and reduced stress levels (Abbott et al., 2003; Sapolsky, 2004). Thus, it may be the link between Assertiveness and alpha status that creates the positive association with welfare and subjective well-being. et al. (2015) found that female rhesus macaques with more similar personalities were more 
Happiness is positive welfare

chimpanzee self-injurious behaviour (Herrelko et al., 2012) and golden snub-nosed monkey illness duration (Jin et al., 2013). Our study adds to this literature by demonstrating that certain personality traits are associated with welfare ratings, which can be used to more carefully monitor capuchins with these traits.

There were limitations to our study. We collected data on locomotor stereotypy using questionnaires but we could not assess the effect of type of stereotypy. Furthermore, we did not examine other types of stereotypical behaviour. This may be important as different types of stereotypy (pacing, rocking, oral) may be related to different aspects of welfare. The stereotypy data was also collected a year after the welfare ratings, which may mean that some of the reported stereotypic behaviour may have developed during that time. However, the strong association between welfare and SWB suggest this may not be the case. Additionally, we included stereotypy to check the validity of the welfare questionnaire, but lacked an equivalent positive welfare indicator such as grooming. traditional assessment methods, may be a viable and practical tool. These findings also show that to account for welfare we need to expand our definition to include positive states of subjective well-being or happiness. Finally, this study reaffirms the strong links, identified in other species, including humans, between personality and welfare.

\section{Acknowledgements}


Happiness is positive welfare

Abbott, D., Keverne, E., Bercovitch, F., Shively, C., Mendoza, S., Saltzman, W., Snowdon, C., Ziegler, T., Banjevic, M., Garland, T., Sapolsky, R., 2003. Are subordinates always stressed? A comparative analysis of rank differences in cortisol levels among primates. Horm. Behav. 43, 67-82. doi:10.1016/S0018-506X(02)00037-5

Akinyi, M.Y., Tung, J., Jeneby, M., Patel, N.B., Altmann, J., Alberts, S.C., 2013. Role of grooming in reducing tick load in wild baboons (Papio cynocephalus). Anim. Behav. 85, 559-568. doi:10.1016/j.anbehav.2012.12.012

Barton, K., 2015. MuMIn: Multi-model inference. R package version 1.9.13. Version 1, 18. doi:citeulike: 11961261

Boccia, M.L., Laudenslager, M., Reite, M.L., 1988. Food distribution, dominance, and aggressive behaviors in bonnet macaques. Am. J. Primatol. 16, 123-130. doi:10.1002/ajp.1350160203

Boissy, A., Manteuffel, G., Jensen, M.B., Moe, R.O., Spruijt, B., Keeling, L.J., Winckler, C., Forkman, B., Dimitrov, I., Langbein, J., Bakken, M., Veissier, I., Aubert, A., 2007. Assessment of positive emotions in animals to improve their welfare. Physiol. Behav. 92, 375-397. doi:10.1016/j.physbeh.2007.02.003

Broom, D.M., 2007. Quality of life means welfare: How is it related to other concepts and assessed? Anim. Welf. 16, 45-53.

Broom, D.M., 2006. Behaviour and welfare in relation to pathology. Appl. Anim. Behav. Sci. 97, 73-83. doi:10.1016/j.applanim.2005.11.019

Broom, D.M., 1991. Animal welfare: concepts and measurement. J. Anim. Sci. 69, 41674175. doi:/1991.69104167x

Broom, D.M., 1988. The scientific assessment of animal welfare. Appl. Anim. Behav. Sci. 20, 5-19. doi:10.1016/0168-1591(88)90122-0

Broom, D.M., Johnson, K.G., 1993. Stress and animal welfare, Animal Welfare. Chapman and Hall, London.

Capitanio, J.P., Blozis, S., Snarr, J., Steward, A., McCowan, B., 2015. Do "birds of a feather flock together" or do "opposites attract"? Behavioral responses and temperament predict success in pairings of rhesus monkeys in a laboratory setting. Am. J. Primatol. 1-11. doi:10.1002/ajp.22464

Coelho Jr, A.M., Turner, S.A., Bramblett, C.A., 1983. Allogrooming and social status: An assessment of the contributions of female behavior to the social organization of hamadryas baboons (Papio hamadryas). Primates 24, 184-197. doi:10.1007/BF02381081

Cohen, S., Kaplan, J., Cunnick, J.E., Manuck, S.B., Rabin, B.S., 1992. Chronic social stress, fffiliation, and cellular immune response in nonhuman primates. Psychol. Sci. 3, 301304. doi:10.1111/j.1467-9280.1992.tb00677.x

Crofoot, M.C., Rubenstein, D.I., Maiya, A.S., Berger-Wolf, T.Y., 2011. Aggression, grooming and group-level cooperation in white-faced capuchins (Cebus capucinus): Insights from social networks. Am. J. Primatol. 73, 821-833. doi:10.1002/ajp.20959

Davenport, M.D., Lutz, C.K., Tiefenbacher, S., Novak, M.A., Meyer, J.S., 2008. A rhesus monkey model of self-Injury: Effects of relocation stress on behavior and neuroendocrine function. Biol. Psychiatry 63, 990-996. doi:10.1016/j.biopsych.2007.10.025 
Happiness is positive welfare

Diener, E., 2009. Subjective well-being, in: The Science of Well-Being: The Collected Works of Ed Diener. pp. 11-58. doi:10.1007/978-90-481-2350-6

Diener, E., Chan, M.Y., 2011. Happy people live longer: Subjective well-being contributes to health and longevity. Appl. Psychol. Heal. Well-Being 3, 1-43. doi:10.1111/j.17580854.2010.01045.x

Diener, E., Oishi, S., Lucas, R.E., 2003. Personality, culture, and subjective well-being: Emotional and cognitive evaluations of life. Annu. Rev. Psychol. 54, 403-425. doi:10.1146/annurev.psych.54.101601.145056

Dinno, A., Dinno, M., 2010. R package "paran.”

Downey, R.G., King, C., 1998. Missing data in Likert ratings: A comparison of replacement methods. J. Gen. Psychol. 125, 175-91. doi:10.1080/00221309809595542

Fragaszy, D.M., Visalberghi, E., Fedigan, L.M., 2004. The Complete Capuchin: The Biology of the Genus Cebus, Reading. doi:10.1007/s10329-005-0129-9

Gartner, M.C., Weiss, A., 2013. Scottish wildcat (Felis silvestris grampia) personality and subjective well-being: Implications for captive management. Appl. Anim. Behav. Sci. 147, 261-267. doi:10.1016/j.applanim.2012.11.002

Gelman, A., 2008. Scaling regression inputs by dividing by two standard deviations. Stat. Med. 27, 2865-2873. doi:10.1002/sim.3107

Gorsuch, R.L., 1983. Factor Analysis, 2nd ed. Erlbaum, Hillsdale, NJ.

Gosling, S.D., 2001. From mice to men: What can we learn about personality from animal research? Psychol. Bull. 127, 45-86. doi:10.1037/0033-2909.127.1.45

Gottlieb, D.H., Capitanio, J.P., Mccowan, B., 2013. Risk factors for stereotypic behavior and self-biting in rhesus macaques (Macaca mulatta): Animal's history, current environment, and personality. Am. J. Primatol. 75, 995-1008. doi:10.1002/ajp.22161

Green, T.C., Mellor, D.J., 2011. Extending ideas about animal welfare assessment to include "quality of life" and related concepts. N. Z. Vet. J. 59, 263-271. doi:10.1080/00480169.2011.610283

Herrelko, E.S., Vick, S.J., Buchanan-Smith, H.M., 2012. Cognitive research in zoo-housed chimpanzees: Influence of personality and impact on welfare. Am. J. Primatol. 74, 828840. doi:10.1002/ajp.22036

Horn, J.L., 1965. A rationale and test for the number of factors in factor analysis. Psychometrika 30, 179-185. doi:10.1007/BF02289447

IUCN, 2014. IUCN Red List of Threatened Species [WWW Document]. Version 2013.1. URL www.iucnredlist.org

Janson, C.H., 1985. Aggresive competition and individual food consumption in wild brown capuchin monkeys (Cebus apella). Behav. Ecol. Sociobiol. 18, 125-138. doi:10.1007/BF00299041

Jin, J., Su, Y., Tao, Y., Guo, S., Yu, Z., 2013. Personality as a predictor of general health in captive golden snub-nosed monkeys (Rhinopithecus roxellana). Am. J. Primatol. 75, 524-533. doi:10.1002/ajp.22127

King, J.E., Landau, V.I., 2003. Can chimpanzee (Pan troglodytes) happiness be estimated by human raters? J. Res. Pers. 37, 1-15. doi:10.1016/S0092-6566(02)00527-5

Laule, G.E., Bloomsmith, M. a., Schapiro, S.J., 2003. The use of positive reinforcement training techniques to enhance the care, management, and welfare of primates in the laboratory. J. Appl. Anim. Welf. Sci. 6, 163-173. 
Happiness is positive welfare

\section{doi:10.1207/S15327604JAWS0603_02}

Lefevre, C.E., Wilson, V.A.D., Morton, F., Brosnan, S.F., Paukner, A., Bates, T.C., 2014 Facial width-to-height ratio relates to alpha status and assertive personality in capuchin monkeys. PLoS One 9. doi:10.1371/journal.pone.0093369

Leinfelder, I., de Vries, M., Deleu, R., Nelissen, M., 2001. Rank and grooming reciprocity among females in a mixed-sex group of captive hamadryas baboons. Am. J. Primatol. 55, 25-42. doi:10.1002/ajp.1036

Lutz, C.K., Well, A., Novak, M. a., 2003. Stereotypic and self-injurious behavior in rhesus macaques: A survey and retrospective analysis of environment and early experience. Am. J. Primatol. 60, 1-15. doi:10.1002/ajp.10075

Mason, G.J., 1991. Stereotypies: a critical review. Anim. Behav. doi:10.1016/S00033472(05)80640-2

Mason, G.J., Latham, N.R., 2004. Can't stop, won't stop: Is stereotypy a reliable animal welfare indicator? Anim. Welf. 13, S57-S70.

McMillan, F., 2005. Mental wellness: The concept of quality of life in animals, in: Mental Health and Well-Being in Animals.

Meagher, R.K., 2009. Observer ratings: Validity and value as a tool for animal welfare research. Appl. Anim. Behav. Sci. 119, 1-14. doi:10.1016/j.applanim.2009.02.026

Morton, F., Lee, P.C., Buchanan-Smith, H.M., Brosnan, S.F., Thierry, B., Paukner, A., de Waal, F.B.M., Widness, J., Essler, J.L., Weiss, A., 2013. Personality structure in brown capuchin monkeys (Sapajus apella): comparisons with chimpanzees (Pan troglodytes), orangutans (Pongo spp.), and rhesus macaques (Macaca mulatta). J. Comp. Psychol. 127, 282-298. doi:10.1037/a0031723

Parr, L., Matheson, M., Bernstein, I., de Waal, F.B.M., 1997. Grooming down the hierarchy: allogrooming in captive brown capuchin monkeys, Cebus apella. Anim. Behav. 54, 361367. doi:10.1006/anbe.1996.0419

Pinheiro, J., Bates, D., DebRoy, S., Sarkar, D., R Development Core Team, 2012. nlme: Linear and Nonlinear Mixed Effects Models. October.

R Development Core Team, 2014. R Development Core Team. R A Lang. Environ. Stat. Comput.

Rushen, J., 1991. Problems associated with the interpretation of physiological data in the assessment of animal welfare. Appl. Anim. Behav. Sci. doi:10.1016/01681591(91)90170-3

Sandvik, E., Diener, E., Seidlitz, L., 1993. Subjective Well-Being - the Convergence and Stability of Self-Report and Non-Self-Report Measures. J. Pers. 61, 318-342. doi:10.1111/j.1467-6494.1993.tb00283.x

Sapolsky, R.M., 2004. Social status and health in humans and other animals. Annu. Rev. Anthropol. 33, 393-418. doi:10.1146/annurev.anthro.33.070203.144000

Shrout, P.E., Fleiss, J.L., 1979. Intraclass correlations: uses in assessing rater reliability. Psychol. Bull. 86, 420-428. doi:10.1037/0033-2909.86.2.420

Shutt, K., MacLarnon, A., Heistermann, M., Semple, S., 2007. Grooming in Barbary macaques: better to give than to receive? Biol. Lett. 3, 231-233. doi:10.1098/rsbl.2007.0052

Terry, R.L., 1970. Primate grooming as a tension reduction mechanism. J. Psychol. 76, 129136. doi:10.1080/00223980.1970.9916830 
Happiness is positive welfare

Tetley, C.L., O'Hara, S.J., 2012. Ratings of animal personality as a tool for improving the breeding, management and welfare of zoo mammals. Anim. Welf. 21, 463-476. doi: $10.7120 / 09627286.21 .4 .463$

USDA, 2008. Animal Welfare Act.

Vandeleest, J.J., McCowan, B., Capitanio, J.P., 2011. Early rearing interacts with temperament and housing to influence the risk for motor stereotypy in rhesus monkeys (Macaca mulatta). Appl. Anim. Behav. Sci. 132, 81-89. doi:10.1016/j.applanim.2011.02.010

Vazire, S., Gosling, S.D., Dickey, A.S., Schapiro, S.J., 2007. Measuring personality in nonhuman animals, in: Handbook of Research Methods in Personality Psychology. pp. 190-206. doi:10.1002/zoo.20379

Weiss, A., Adams, M.J., King, J.E., 2011a. Happy orang-utans live longer lives. Biol. Lett. 7, 872-874. doi:10.1098/rsbl.2011.0543

Weiss, A., Adams, M.J., Widdig, A., Gerald, M.S., 2011b. Rhesus macaques (Macaca mulatta) as living fossils of hominoid personality and subjective well-being. J. Comp. Psychol. 125, 72-83. doi:10.1037/a0021187

Weiss, A., Inoue-Murayama, M., Hong, K.W., Inoue, E., Udono, T., Ochiai, T., Matsuzawa, T., Hirata, S., King, J.E., 2009. Assessing chimpanzee personality and subjective wellbeing in japan. Am. J. Primatol. 71, 283-292. doi:10.1002/ajp.20649

Weiss, A., King, J.E., Perkins, L., 2006. Personality and subjective well-being in orangutans (Pongo pygmaeus and Pongo abelii). J. Pers. Soc. Psychol. 90, 501-511. doi:10.1037/0022-3514.90.3.501

Whitham, J.C., Wielebnowski, N., 2009. Animal-based welfare monitoring: using keeper ratings as an assessment tool. Zoo Biol. 28, 545-560. doi:10.1002/zoo.20281

Wittig, R.M., Boesch, C., 2003. Food competition and linear dominance hierarchy among female chimpanzees of the Ta1 National Park. Int. J. Primatol. 24, 847-867.

Yeates, J.W., Main, D.C.J., 2008. Assessment of positive welfare: a review. Vet. J. 175, 293 300 . 